\title{
Freighter Loading Efficiency at Airports for International Air Express
}

\author{
Hua-An Lu',a and Chi-Sheng Chung ${ }^{2}$ \\ ${ }^{1}$ Professor, Department of Shipping and Transportation Management, National Taiwan Ocean University, 2 Pei-Ning Road, Keelung 202, \\ Taiwan, R.O.C. \\ ${ }^{2}$ Ramp Agent-lead, Ramp Operations, FedEx Express Co., 8-1 Hang-Chin North Road, Tao Yuan Hsien 337, Taiwan, R.O.C.
}

\begin{abstract}
Loading efficiency of freighters plays an indispensable role for the service performance of international air express companies. This study examined the priorities of factors to affect freighter loading efficiency at Taoyuan International airport (TPE) with an analytic hierarchy process (AHP). Unit load device (ULD) inventory control, load factor and load plan were ranked top 3 from 15 factors by practical experts. This study used the technique for order preference by similarity to ideal solution (TOPSIS) to evaluate 26 flights of MD11 freighters operated by an international air express company at TPE. The results revealed that the performance ranges between the best and worst flights were obvious.
\end{abstract}

\section{Introduction}

International air express provides door-to-door services over the world. Every sector of operation chains is running against time from the beginning of the pickup to the end of final delivery. One of the key factors for a successful service is the process of aircraft loading at airports. Loading performance is not only to expense the least time to load cargo on aircraft but also to spent the least resources to carry as much cargo as available. Aircraft loading efficiency affects the results of express services. There might be many factors to affect the loading efficiency of freighters at airports for international air express. Actually, the freighter capacities are the most important resource supply in the air cargo and logistics community. It has become a crucial topic to keep a well performance of cargo shipping for freighter flights with efficient shipment carries [1-2].

Feng et al. [3] reviewed studies dedicated on air cargo operations from the practical perspectives of airlines, freight forwarders, and terminal service providers. Some mentioned acitivies could affect airlines operation performance at airports, such as improving load factors, allocating cargo space-allotments, resource management of terminal staff, shipments tendered, dangerous goods control, cargo routing and scheduling, packing validation, etc. According to the literature reviews of Brandt and Nickel [4], previous studies focused on the airport operation processes with a variety of operational research techniques. The main topics of air cargo loading can be divided into aircraft configuration problem, build-up scheduling problem, air cargo palletization problem, and weight and balance problem.

Currently most of air cargo are built up into the air unit load devices (ULDs), which mainly include

\footnotetext{
${ }^{a}$ Corresponding author: halu@ntou.edu.tw
}

containers and pallets, for loading on the appropriate deck positions in aircraft. ULDs inventory control concerned about equipment provision for loading operations [5]. The assemblies of ULDs in a load plan affect not only available capacities of loaded freights which performance reflects on the load factor of every flight but ULDs repositioning also [6]. Special contours of containers and flexible stacks of pallets affect the sufficient uses of equipment capacity. The selection of ULDs must consider the 3-dimension scales, weight limits, stacking stability, as well as the different characteristics of shipment and mixed build-up with each other of different items [7-8].

While ULDs are loaded on the aircraft, the allotment of ULDs have to be planned in consideration of aircraft interior contour, weight limits on structure, and resulted position of aircraft center of gravity (CG). This problem is referred to the aircraft weight and balance (W\&B). These conditions are all set as loading constraints [9-11] based on a decision objective function, such as maximization of cargo transport profits [12], or maximization of shipment loads [13]. The decision of such kind contents will be more complicated if taking into account multiple flight legs [14] or combining with ULDs selection [15].

For the international air express field, most of previous studies explored the flow distribution patterns within a hub-and-spoke network [16-18]. The proposed models in these studies could also decide shipment consolidation and distribution at hub and spoke airports for the container loads and the less than container loads.

Most reviewed papers related to loading operations were focused on all-cargo or combined airlines. However, international air express operates significantly different from both kinds of airlines. This study aims to explore 
key factors affecting the loading efficiency of freighters at airports for international air express. This ultimate goal can be evaluated with different dimensions of operation processes. Each aspect took into account the attributed considerations that can be evaluated the efficiency in detail. This study applied the analytic hierarchy process (AHP) to investigate experts of an international air express company serving in Taiwan at the Taoyuan International Airport (IATA code: TPE) in constructing an evaluation framework. The results of evaluated weights for factors framework were also applied to compare the loading efficiency of selected MD11F flights using the technique for order preference by similarity to ideal solution (TOPSIS).

\section{Methodologies}

This study exploited the AHP with a rank pair-wise comparison (RPC) concept [19] to investigate expert opinions and then to calculate the weights of affecting factors. Experts suggested some numerical indexes being the data to represent the factors. The application of TOPSIS is appropriate to evaluate loading efficiency of air express freighters for export operations.

\subsection{AHP with RPC}

The AHP has been one of the popular multi-criteria decision-making methods to be successfully applied to different fields. The purpose of an AHP is to measure relative comparison among factors and then, if need, to evaluate the possible alternatives [20]. First, an AHP requires to construct a systematic and decisive hierarchical framework that composes of goal, levels for evaluated criteria, and possible selectable alternatives. Then, one can allocate the relative weights, which might be examined through group decision of experts by several academic studies, for evaluated criteria and attributed factors. Furthermore, if there are alternatives required to be ranked, the performance evaluation of all alternatives on all decision criteria need to be further measured.

The pair-wise comparison among entries under a common attribute is the core of executing an AHP. A matrix, called pair-wise comparison matrix, presents the compared results between every two entries in which the values of symmetrical elements in this matrix are reciprocal. Through the linear algebra calculation, one can decide the relative weights for every entry. Normally, the pair-wise comparison results follow the perfect transitivity property, i.e., the value of entry $a$ compared to entry $b$ is equal to the multiple between the value of entry $a$ compared to entry $c$ and the value of entry $c$ compared to entry $b$. An AHP allows deciders to present a slight variety on this property but to satisfy an acceptably consistent level.

However, there are some experienced drawbacks in executing an AHP to collect the opinions of a large group of respondents. First, too many comparative entries generally make the respondents, particularly those who without any experience on pair-wise comparison, unable to discriminate the relative weights that are necessary to reach the acceptably consistent level. For example, the number of comparisons is $\left(n^{2}-n\right) / 2$ for $n$ entries. Second, inconsistency in responses possibly takes place when respondents encounter entries with closer perceived relationships. The reason for this phenomenon might be that respondents do not rank their priorities in advance. Furthermore, too complicated framework listing too many pair-wise comparison queries make respondents chaos during the process of filling the opinions. The original opinions of respondents might be distorted because of repetitive queries for reaching a minimum consistency.

The RPC [19] is one of approaches to overcome above drawbacks of the traditional pair-wise comparison method. This approach asks respondents to express the priorities of the involved entries and subsequently assess the relative weights for two consecutive ranks. The number of pair-wise comparison is reduced to $n-1$ for $n$ entries. Using the transitive rule, the scale adjustment rule and the reciprocal principle, one can yield an RPC matrix with complete consistency. This approach is rather appropriate to collect opinions for a large group. The whole execution process is designed as follows.

Step 1: Distribute questionnaires to all respondents and then collect their opinions.

Step 2: Construct all respondents' pair-wise comparison matrixes by the following RCP steps [19].

(a) According to the transitive rule, calculate the values for other nonconsecutive comparison elements with the consecutive comparison results.

(b) Adjust the values for these elements according to the scale adjustment rule.

(c) Fill in the values for other elements according to the reciprocal principle.

Step 3: Combine all respondents' pair-wise comparison matrixes which elements are calculated by the geometric means of all corresponding values in all respondent's pair-wise comparison matrixes.

Step 4: Calculate the relative weights for entries in all tiers with these matrixes, using the average of normalized columns approach as Equation (1).

$$
w_{i}=1 / n\left\{\sum_{j=1 \text { to } n}\left(a_{i j} / \sum_{i=1 \text { to } n} a_{i j}\right)\right\}
$$

Step 5: Distribute the overall relative weights for all subcriteria.

Step 6: Rank the priorities for all sub-criteria with the overall relative weights.

\subsection{TOPSIS}

The TOPSIS approach appropriates to evaluate a variety of alternatives with multiple quantified factors with positive and negative influence. Its concept is to find an alternative that is closest to the defined positive ideal solution (PIS) and furthest with the defined negative ideal solution (NIS). The defined PIS can be the maximal values of benefit criteria and minimal values of cost criteria and vice versa for the defined NIS.

Following the steps proposed by Hwang and Yoon [21], the implementation of TOPSIS for a given matrix 
with assigned rates to the criteria and to the alternatives is described as the following:

Step 1: Normalize this evaluation matrix.

Step 2: Construct the weighted decision matrix.

Step 3: Define the PIS and NIS.

Step 4: Calculate the distances to the PIS and NIS for every alternative.

Step 5: Compute the closeness coefficient with the ideal solutions for each alternative.

Step 6: Rank the preference orders of alternatives.

\section{Investigation}

This research has firstly to construct the evaluation framework for the ultimate goal, i.e. examining the factor priorities influencing the loading efficiency of freighters. Then, this study executed sampling investigation to the studied company. The priorities of sub-criteria can be evaluated with the AHP and RPC.

\subsection{Analytic hierarchy}

This study firstly examined the practice of aircraft loading for express freighters at the airport, and then to list 5 criteria and 15 attributed sub-criteria for reviews of 6 practical experts in our focus group. The five criteria consist of ULD uses, cargo load planning, aircraft weight and balance, resources utilisation, and operation performance. Except ULD uses with $83.3 \%$ and operation performance with $66.7 \%$ of agreement, other three criteria were all totally agreed. Nine sub-criteria received entirely agreement, while 5 factors and 1 item obtained $83.3 \%$ and $66.7 \%$ agreement, respectively. The evaluated hierarchy is shown in Figure 1.

\subsection{Sampling}

A questionnaire designed for the rank pair-wise comparison with 7-point measure scales from 1 for the same important to 7 for extremely important. Respondents can give the sequence of importance for the evaluated elements, and then express the importance level for each consecutive element pair. This questionnaire evaluates 6 pair-wise comparison items with one matrix for criterion level and 5 matrixes for each sub-criterion levels.

Operation unit at TPE airport of the studied company could provide the required investigation objectives and evaluation data resources at TPE. This availability facilitated the whole studied process. In total, 15 ramp operation technicians of the studied company working at TPE airport responded questionnaires during April $1^{\text {st }}$ to $30^{\text {th }} 2019$. Twelve experts had the experience of above 20 years and other 3 respondents with less than 10 years. All of questionnaires are effective.

\subsection{Factor priorities}

The opinions of 15 experts were formulated their own pair-wise comparison matrixes following the calculation mentioned in Section 2.1. Calculating the geometric means for the related elements in the same matrixes to form the final comparison matrixes of group decision. Following Equation (1), the result of factor priorities is shown in Table 1.

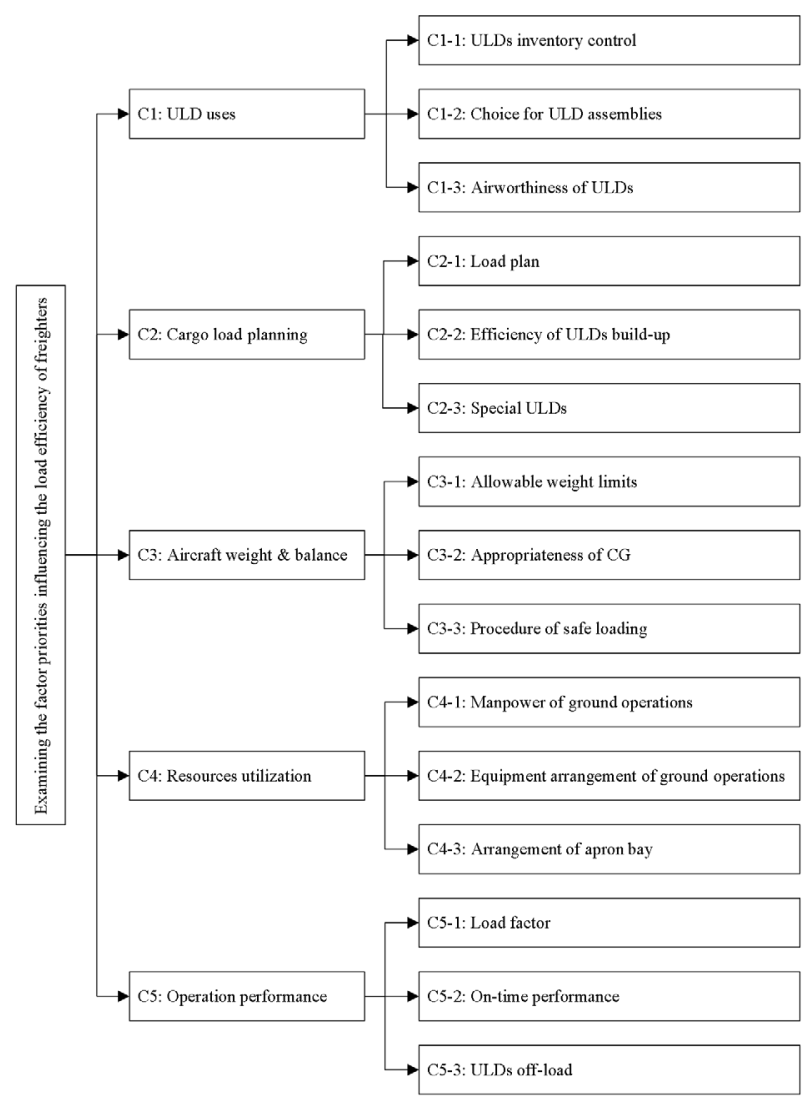

Figure 1. AHP evaluation framework of the study.

Table 1. Weights and ranked priorities.

\begin{tabular}{|c|c|c|c|c|c|c|}
\hline Criteria & $\begin{array}{l}\text { Criterion } \\
\text { weight }\end{array}$ & $\begin{array}{c}\text { Sub- } \\
\text { criteria }\end{array}$ & $\begin{array}{l}\text { Weight } \\
\text { in } \\
\text { criterion }\end{array}$ & $\begin{array}{l}\text { Rank in } \\
\text { criterion }\end{array}$ & $\begin{array}{c}\text { Distributed } \\
\text { weight }\end{array}$ & $\begin{array}{c}\text { Rank in } \\
\text { total }\end{array}$ \\
\hline \multirow{3}{*}{$C 1$} & \multirow{3}{*}{0.2026} & C1-1 & 0.4270 & 1 & 0.0865 & 1 \\
\hline & & $C 1-2$ & 0.3287 & 2 & 0.0666 & 8 \\
\hline & & $C 1-3$ & 0.2443 & 3 & 0.0495 & 14 \\
\hline \multirow{3}{*}{$C 2$} & \multirow{3}{*}{0.2145} & $C 2-1$ & 0.3758 & 1 & 0.0806 & 3 \\
\hline & & $C 2-2$ & 0.2737 & 3 & 0.0587 & 12 \\
\hline & & $C 2-3$ & 0.3504 & 2 & 0.0752 & 4 \\
\hline \multirow{3}{*}{$C 3$} & \multirow{3}{*}{0.1984} & C3-1 & 0.3284 & 2 & 0.0652 & 9 \\
\hline & & C3-2 & 0.3631 & 1 & 0.0720 & 6 \\
\hline & & C3-3 & 0.3084 & 3 & 0.0612 & 11 \\
\hline \multirow{3}{*}{$C 4$} & \multirow{3}{*}{0.1949} & C4-1 & 0.3810 & 1 & 0.0742 & 5 \\
\hline & & $C 4-2$ & 0.3245 & 2 & 0.0632 & 10 \\
\hline & & C4-3 & 0.2945 & 3 & 0.0574 & 13 \\
\hline \multirow{3}{*}{ C5 } & \multirow{3}{*}{0.1897} & $C 5-1$ & 0.4392 & 1 & 0.0833 & 2 \\
\hline & & $C 5-2$ & 0.3618 & 2 & 0.0686 & 7 \\
\hline & & C5-3 & 0.1990 & 3 & 0.0377 & 15 \\
\hline
\end{tabular}

Cargo load planning was ranked first in five criteria, following by the criterion of ULD uses. These two criteria share percentages over one fifth. ULDs inventory control, load factor, and load plan were ranked top 3 in fifteen sub-criteria. They all share the weight ratios of more than 0.08 . In practice, many flights of the studied company at TPE kept a large amount of ULDs for transferring and positioning. A sufficient amount of ULDs can easily allocate shipment with different sizes 
and diverse characteristics. In particular, these flights also required more time to build up containers because of operating on early morning. The factor to control ULDs inventory becomes a critical condition. Load factors is the index to reflect the real performance of freighter operations. Each flight might be affected the results of load factor by different reasons, such as weather conditions, flying distances, and of course load control. The whole processes of export operations for a flight are driven by the load plan. Its contents concern about the occurrence of any extraordinary situation on the ramp.

\section{Case of MD11F}

Some factors influencing freighter loading efficiency might be abstract and negative. Practical experts proposed numerical indexes to express these factors. This study chosen TOPSIS, which can adapt to the sets with positive and negative indexes, to evaluate MD11F flights.

\subsection{Indexes of TOPSIS}

This study used following numerical data to express subcriteria in the evaluation hierarchy through suggestion of practical experts.

(1) ULDs inventory control: the number of left empty ULDs after aircraft departure.

(2) Choice for ULD assemblies: the number of loaded ULDs onto aircraft including ULDs built up at TPE, transferred ULDs, reloaded ULDs, etc.

(3) Airworthiness of ULDs: the number of ULDs without airworthiness.

(4) Load plan: the duration between finishing load plan and aircraft pushback.

(5) Efficiency of ULDs build-up: the number of ULDs built up at TPE and really loaded on the aircraft.

(6) Special ULDs: the number of special ULDs loaded onto the aircraft.

(7) Allowable weight limits: maximal aircraft weight allowed to be loaded.

(8) Appropriateness of CG: the distance between actual $\mathrm{CG}$ position and the most forward allowance position of CG.

(9) Procedure of safety loading: following the existing procedures of the company, 1 for better application than 2.

(10)Manpower of ground operations: the number of workers for ground operations.

(11)Equipment arrangement of ground operations: the number of ground equipment used.

(12)Arrangement of apron bays: the distance between assigned parking bay with the bay closest with the warehouse.

(13)Load factor: actual cargo load weight divided by the available weight capacity.

(14)On-time performance: delay times of flight departure.

(15)ULD off-load: the number of off-load ULDs.

The positive (benefit) subset of sub-criteria includes factors $1,2,4,5,6,7,8$, and 13 , other indexes belong to the negative (cost) subset.

\subsection{Data Collection}

Courtesy of the studied company at TPE airport, this study could collect the data of MD11F flights for a certain period of 2018. These 26 flights, 5 flights per week, departed from TPE and directly landed at the transferring centre of Anchorage airport. They carried transpacific freights to be consolidated with other cargos destined to North America airports.

\subsection{Evaluation results}

The evaluation results for MD11F flights are shown in Table 2. Flight 16 was ranked first, while flight 12 was ranked worst. The comparison between the best and worst flights is shown in Table 3. Except appropriateness of CG, numerical indexes of flight 16 are all much better than those of flight 12. The gap of their closeness coefficient presents obvious.

Table 2. Evaluation results for MD11F flights.

\begin{tabular}{|c|c|c|c|c|}
\hline Flight & $\begin{array}{l}\text { Distance to } \\
\text { PIS }\end{array}$ & $\begin{array}{c}\text { Distance to } \\
\text { NIS }\end{array}$ & $\begin{array}{c}\text { Closeness } \\
\text { coefficient }\end{array}$ & Rank \\
\hline 1 & 0.01720 & 0.06656 & 0.79462 & 11 \\
\hline 2 & 0.02036 & 0.06933 & 0.77301 & 15 \\
\hline 3 & 0.02020 & 0.07028 & 0.77673 & 14 \\
\hline 4 & 0.01692 & 0.07179 & 0.80925 & 7 \\
\hline 5 & 0.01781 & 0.07277 & 0.80336 & 9 \\
\hline 6 & 0.02621 & 0.07058 & 0.72920 & 22 \\
\hline 7 & 0.02561 & 0.06688 & 0.72310 & 23 \\
\hline 8 & 0.02148 & 0.07086 & 0.76741 & 16 \\
\hline 9 & 0.02691 & 0.06890 & 0.71909 & 24 \\
\hline 10 & 0.02377 & 0.07311 & 0.75461 & 20 \\
\hline 11 & 0.01865 & 0.07255 & 0.79552 & 10 \\
\hline 12 & 0.06901 & 0.03270 & 0.32152 & 26 \\
\hline 13 & 0.01933 & 0.07131 & 0.78674 & 13 \\
\hline 14 & 0.01897 & 0.06208 & 0.76597 & 17 \\
\hline 15 & 0.01641 & 0.07246 & 0.81534 & 4 \\
\hline 16 & 0.01101 & 0.07462 & 0.87141 & 1 \\
\hline 17 & 0.01430 & 0.07220 & 0.83473 & 2 \\
\hline 18 & 0.02232 & 0.06962 & 0.75720 & 19 \\
\hline 19 & 0.01767 & 0.07243 & 0.80384 & 8 \\
\hline 20 & 0.02458 & 0.06897 & 0.73727 & 21 \\
\hline 21 & 0.01703 & 0.07290 & 0.81060 & 6 \\
\hline 22 & 0.02781 & 0.06937 & 0.71386 & 25 \\
\hline 23 & 0.02188 & 0.07148 & 0.76566 & 18 \\
\hline 24 & 0.01642 & 0.07262 & 0.81556 & 3 \\
\hline 25 & 0.01909 & 0.07125 & 0.78865 & 12 \\
\hline 26 & 0.01691 & 0.07358 & 0.81308 & 5 \\
\hline
\end{tabular}

Table 3. Comparison between the best and worst flights.

\begin{tabular}{|c|c|c|c|c|}
\hline $\begin{array}{c}\text { Factor } \\
\text { priority }\end{array}$ & Factor & Subset & $\begin{array}{c}\text { Flight 16 } \\
\text { (best) }\end{array}$ & $\begin{array}{c}\text { Flight 12 } \\
\text { (worst) }\end{array}$ \\
\hline 1 & $\mathrm{C} 1-1$ & $\mathrm{P}$ & 182 & 146 \\
\hline 2 & $\mathrm{C} 5-1$ & $\mathrm{P}$ & 1.08653 & 0.75202 \\
\hline 3 & $\mathrm{C} 2-1$ & $\mathrm{P}$ & 275 & 248 \\
\hline 4 & $\mathrm{C} 2-3$ & $\mathrm{P}$ & 5 & 5 \\
\hline 5 & $\mathrm{C} 4-1$ & $\mathrm{M}$ & 15 & 15 \\
\hline 6 & $\mathrm{C} 3-2$ & $\mathrm{P}$ & 526 & 581 \\
\hline 7 & $\mathrm{C} 5-2$ & $\mathrm{M}$ & 0 & 34 \\
\hline 8 & $\mathrm{C} 1-2$ & $\mathrm{P}$ & 50 & 45 \\
\hline 9 & $\mathrm{C} 3-1$ & $\mathrm{P}$ & 185,510 & 160,000 \\
\hline 10 & $\mathrm{C} 4-2$ & $\mathrm{M}$ & 8 & 8 \\
\hline 11 & $\mathrm{C} 3-3$ & $\mathrm{M}$ & 15 & 15 \\
\hline 12 & $\mathrm{C} 2-2$ & $\mathrm{P}$ & 15 & 10 \\
\hline 13 & $\mathrm{C} 4-3$ & $\mathrm{M}$ & 0 & 0 \\
\hline 14 & $\mathrm{C} 1-3$ & $\mathrm{M}$ & 2 & 0 \\
\hline 15 & $\mathrm{C} 5-3$ & $\mathrm{M}$ & 0.91304 & 1.00000 \\
\hline
\end{tabular}




\section{Conclusion and Suggestion}

This study has examined the factors influencing the loading efficiency of freighter operations at airports for international air express. An AHP framework to evaluate factor priorities was constructed. Through an investigation of practical experts with a rank pair-wise comparison questionnaire, factor weights were measured to rank the importance. The dimension of cargo load planning was ranked the most important, while ULDs inventory control, load factor and load plan were top 3 factors.

The AHP framework has been applied to the case of MD11F flights of the studied company at TPE with the TOPSIS. The comparison results between the best and worst flights revealed a large and obvious gap on closeness coefficients. Except appropriateness of CG, numerical indexes of the former were all much better than those of the latter.

This study focused only on the export operation of an international air express company and at a specific airport because of the individual requirement on this topic. However, the AHP and TOPSIS proposed in this study can be applied to practical measures for other freighter flights and similar topics, or even for the operation of other companies and airports, in the future research. It is noted that the weights of factors may be affected and changed because of different flight operation characteristics in air express network. Furthermore, other air cargo business models, such as combination carriers, may require a slight change on the evaluated factors according to their operation properties.

\section{Acknowledgement}

This study thanks to the financial support of Ministry of Science Technology of Taiwan with the granted number MOST-108-2410-H-019-023-MY2.

\section{References}

1. R. Merkert, E.V. de Voorde, J. de Wit, J. Air Transp. Manag. 37, 10-19 (2017)

2. L. Budd, S. Ison, J. Air Transp. Manag. 61, 34-40 (2017)

3. B. Feng, Y. Li, Z.J.M. Shen, Transp. Res. C 56, 263280 (2015)

4. F. Brandt, S. Nickel, Eur. J. Oper. Res., Available online doi.org/10.1016/j.ejor.2018.07.013. (to be published)

5. H.A. Lu, C.Y. Chen, J. Mar. Sci. \& Tech. 20(4), 431440 (2012)

6. H.A. Lu, C.Y. Chen, J. Air Transp. Manag. 17, 94$100(2011)$

7. F.T.S. Chan, R. Bhagwat, N. Kumar, M.K. Tiwari, P. Lam, Expert Syst. Appl. 31, 472-485 (2006)

8. C. Paquay, M. Schyns, S. Limbourg, Int. Trans. Oper, Res, 23(2), 187-213 (2014)

9. O. Larsen, G. Mikkelsen, Eur. J. Oper. Res. 4(6), 367-373 (1980)

10. S. Limbourg, M. Schyns, G. Laorte, J. Oper. Res. Soc. 63, 1271-1283 (2012)

11. W. Vancroonenburg, J. Verstichel, K. Tavernier, G.V. Berghe, Transp. Res. E 65, 70-83 (2014)

12. I. Brosh, J. Oper. Res. 8(1), 40-46 (1981)

13. M. Mongeau, C. Bes, IEEE Trans. on Aero. Ele. Syst. 39(1), 140-150 (2003)

14. V. Lurkin, M. Schynes, Eur. J. Oper. Res. 61, 1-5 (2015)

15. N. Dahmani, S. Krichen, Int. J. Oper. Res. 27(1-2), 62-84 (2016)

16. S. Yan, C.-T. Lo, Y.-L. Shih, Transp. Plan. Tech. 29(6), 445-470 (2006)

17. S. Yan, Y.-L. Shih, F.-Y. Shiao, Transp. Res. E 44, 555-575 (2008)

18. C.-H. Tang, Transp. Res. E 47, 520-531 (2011)

19. H.A. Lu, R.R. Liu, J. Air Transp. Manag. 37, 10-19 (2014)

20. T.L. Saaty, The analytic hierarchy process (McGraw-Hill, New York, 1980)

21. C.L. Hwang, K.P. Yoon, Multiple attribute decision making: methods and applications, a state-of-the-art survey (Springer-Verlang, Berline, 1981) 